\title{
Prevalence and Risk Factors Associated with Adherence to Antiretroviral Therapy in HIV-Infected Adults in a Tertiary Care Hospital in Mexico
}

Xochipa-García Natali+, Mata-Marín José Antonio², Alcalá-Martínez Enrique¹, Domínguez-Hermosillo Juan Carlos²*, Huerta-García Gloria ${ }^{3}$, Manjarrez-Tellez Bulmaro² and Gaytán-Martínez Jesus²

${ }^{1}$ Epidemiology Department, National Medical Center, "La Raza", IMSS. Distrito Federal, México

2Infectious Diseases Department, National Medical Center, "La raza", IMSS. Distrito Federal, México

${ }^{3}$ Pediatric Infectious Diseases Department, National Medical Center, "Siglo XXI", IMSS. Distrito Federal, México

\begin{abstract}
Background: Human immunodeficiency virus (HIV) infection has become a disease in epidemiological transition since the introduction of antiretroviral therapy (ART); however, its control depends on adherence to therapy. There are some studies in Mexico regarding such adherence but they have had heterogeneous results. We aimed to determine the prevalence of ART adherence and risk factors associated with non-adherence among HIV-infected adults in a tertiary care hospital in Mexico.
\end{abstract}

Methods: This was a cross-sectional study conducted at the Hospital de Infectología, "La Raza" National Medical Center, Mexico City. The subjects of the study were HIV-infected adults after at least 6 months on ART. They answered a questionnaire involving socio-demographics, biochemical, and clinical variables. Adherence was measured using the simplified medication adherence questionnaire

Results: Three hundred seventy-six HIV-infected patients were included in the study. The median age was 35 years (interquartile range, IQR, 29-44) and most of them were men (79.3\%). Among the participants, $73 \%(95 \%$ confidence interval, $\mathrm{Cl}, 68.2-77.4 \%$ ) adhered to the medications prescribed. Factors associated with good adherence were being male (odds ratio, OR, $0.43 ; 95 \% \mathrm{Cl}, 0.22-0.83$ ) and the absence of alcohol use $(\mathrm{OR}, 0.27 ; 95 \% \mathrm{Cl}, 0.12$ 0.58 ); factors associated with non-adherence were a history of $\geq 2 \mathrm{ART}$ regimens (OR, 1.95; $95 \% \mathrm{Cl}, 1.05-3.62)$, time spend attending medical care or receiving drugs (OR, 2.40; $95 \% \mathrm{Cl}, 1.22-4.70)$, and persistent viremia (OR, 2.72; $95 \%$ $\mathrm{Cl}, 1.42-5.19 ; \mathrm{P}<0.005)$

Conclusion: In the era of ART as prevention for transmission of HIV as well as treatment for HIV-positive individuals irrespective of CD4 cell counts, the importance of adherence has grown. Treatment failure reduces future treatment options and therefore long-term clinical success as well as increases the possibility of developing drug resistant mutations. Being male and a lack of alcohol use were factors associated with higher rates of adherence, whereas previous use of ART, more ARV regimens, and a longer time waiting for medical care or drugs, were associated with nonadherence in this HIV-infected population. Incomplete ART adherence is associated with persistent viremia.

Keywords: HIV; ART; Adherence; Virological failure; Risk factors; HIV-1 viral load; CD4+ cells count

\section{Introduction}

In Mexico, antiretroviral therapy (ART) coverage for human immunodeficiency virus (HIV) infection is about $85 \%$; the aim is to achieve optimal and prolonged HIV-1 RNA viral load suppression, if possible to $<50$ copies $/ \mathrm{mL}$, and patient adherence is necessary [1,2]. ART suppresses the HIV-1 RNA viral load, leading to immunological recovery and clinical improvements $[3,4]$. Success in achieving good outcomes relies on high levels of ART adherence: preferably $95 \%$ or more to suppress HIV replication, and $80 \%$ or more to protect the immune system $[5,6]$.

The World Health Organization defines adherence as the degree to which people's behavior taking medication, keeping on a diet, and changes in lifestyle corresponds with agreed recommendations from a health care provider. Poor adherence compromises health improvements and leads to the wastage of treatment resources that are already limited $[7,8]$. Non-adherence to recommended therapies is a global problem and has been observed for all diseases, but adherence to ART differs among countries according to clinical, economic, and socio-demographic factors [9]. A meta-analysis of 19 case-controlled studies found that adherence to ART was significantly lower in patients with adverse reactions to antiretroviral drugs than among those without them [10].
A cross-sectional study conducted in Barcelona, Spain, in 2002 used the simplified medication adherence questionnaire (SMAQ) to validate adherence and applied it to $3004 \mathrm{HIV}$-infected patients. The test consists of six questions and the study found a prevalence of ART adherence of $68 \%$ in that population [11]. A study conducted in Mexico on $93 \mathrm{HIV}$-infected patients found that $43 \%$ of participants were nonadherent; however, factors associated with nonadherence were not evaluated [12]. In our country, information about ART adherence, the impact that it has on HIV-infected patients, and the associated risk factors is still limited. The aim of this study was to determine the prevalence of ART adherence and the risk factors associated with

*Corresponding author: Juan Carlos Domínguez Hermosillo, Hospital de Infectología, Centro Médico Nacional "La Raza”. Seris y Jacarandas s/n, Colonia "La Raza”, Del Azcapotzalco, CP 02990 Ciudad de México, D.F, Tel: + 52-5557245900; E-mail: cardomher@gmail.com

Received September 21, 2015; Accepted Novmeber 02, 2015; Published November 07, 2015

Citation: Natali XG, Antonio MMJ, Enrique AM, Carlos DHJ, Gloria HG et al (2015) Prevalence and Risk Factors Associated with Adherence to Antiretroviral Therapy in HIV-Infected Adults in a Tertiary Care Hospital in Mexico. J AIDS Clin Res 6: 518. doi:10.4172/2155-6113.1000518

Copyright: ( 2015 Natali XG, et al. This is an open-access article distributed unde the terms of the Creative Commons Attribution License, which permits unrestricted use, distribution, and reproduction in any medium, provided the original author and source are credited. 
nonadherence in this HIV-infected population.

\section{Methods}

\section{Design}

A cross-sectional study was conducted to assess the adherence to ART among HIV-1-infected patients who attended the hospital de Infectología, "La Raza" National Medical Center.

\section{Patients}

The subjects of the study were people infected with HIV-1 $>18$ years old, on ART for-at least 6 months; and $\geq 2$ determinations of CD4+ T cell count and HIV-1 RNA viral load during the regimen, separated by $8-12$ weeks. Patients with major psychiatric disorders or with incomplete information were excluded.

\section{Measurements}

In the context of HIV, ART can be defined as the "ability of the person living with HIV/AIDS to be involved in choosing, starting, managing, and maintaining a given therapeutic medication regimen to control HIV replication and to improve immune function. Adherence to ART was assessed through a structured questionnaire during direct interviews with the participants. The SMAQ questionnaire was used to evaluate the prevalence of adherence to ART in this population. Another questionnaire, "Rule AMAI NSE $8 \times 7$ ", was applied to determine the patients' sociodemographic characteristics such as gender, age, place of residence, alcohol use, use or supply of recreational drugs, marital status, partner status, educational level, and time spent waiting for medical care $[13,14]$.

Medical records were reviewed to collect patient information about the time of the HIV infection diagnosis, history of ART regimens, clinical stage according to CDC and CD4+ cell counts, and HIV-1 RNA viral load. Virologial failure was defined as two determinations of HIV1 RNA viral load with more than 200 copies/mL, blip was defined as a single detectable viral load.

\section{Statistical analyses}

Patients were stratified by age, gender, marital and socioeconomic status, educational level, and antiretroviral regimen used. Groups were compared according to adherence level. The Kolmogorov-Smirnov test was used to determine normality of distribution of the data. Baseline characteristics were summarized using medians and interquartile ranges (IQRs) for continuous variables and proportions for categorical variables. Risk factors associated with adherence were tested using a bivariate analysis, which estimated crude odds ratios (ORs) and 95\% confidence intervals (CIs). Fisher's exact test and Chi-squared tests were also applied. Independent risk factors associated with adherence were identified in the binomial logistic regression model that included statistically significant variables from the bivariate analysis. All analyses were carried out using IBM SPSS (v. 21.0; IBM Corp., Armonk, NY, USA) and EpiData (v. 3.8; EpiData Association, Odense, Denmark) software. $\mathrm{P}$ values $<0.05$ were considered significant.

\section{Results}

Of the 387 patients invited, 376 agreed to participate; $79 \%$ were men. The median age was 35 years (IQR, 29-44). Most of the patients were living in Mexico City (60\%), 65.2\% were married, and 54.3\% were men who had sex with men (MSM). Twenty-nine percent had completed high school, and $44.1 \%$ were employees (Table 1). Bivariate analysis was applied to investigate associations between all potential variables from this study, and self-reported adherence (Table 2).

\section{Adherence measurement}

The overall prevalence of ART adherence was 73\% (95\% CI, 68.2-77.4), and this was evaluated in different categories (Table 3).

\begin{tabular}{|c|c|c|}
\hline Characteristics & $\mathbf{N}$ & $\%$ \\
\hline \multicolumn{3}{|l|}{ Sex } \\
\hline Male & 298 & 79.3 \\
\hline \multicolumn{3}{|l|}{ Age (y) } \\
\hline $18-29$ & 100 & 26.6 \\
\hline $30-39$ & 133 & 35.4 \\
\hline $40-49$ & 81 & 21.5 \\
\hline$\geq 50$ & 62 & 16.5 \\
\hline \multicolumn{3}{|l|}{ Sexual preference } \\
\hline Heterosexual & 152 & 40.4 \\
\hline MSM & 204 & 54.3 \\
\hline Bisexual & 20 & 5.3 \\
\hline \multicolumn{3}{|l|}{ Marital status } \\
\hline Single & 245 & 65.2 \\
\hline Married & 56 & 14.9 \\
\hline Living with partner & 46 & 12.2 \\
\hline Other & 29 & 7.7 \\
\hline \multicolumn{3}{|l|}{ Educational level } \\
\hline Lack of schooling & 2 & 0.5 \\
\hline Elementary school & 26 & 6.9 \\
\hline Junior high school & 98 & 26.1 \\
\hline High school & 109 & 29.0 \\
\hline Degree studies & 95 & 25.3 \\
\hline Postgraduate studies & 46 & 12.2 \\
\hline \multicolumn{3}{|l|}{ Concomitant conditions } \\
\hline Diabetes & 8 & 2.1 \\
\hline Hypertension & 9 & 2.4 \\
\hline Chronic Gastritis & 9 & 2.4 \\
\hline Ischemic Cardiopathy & 3 & 0.8 \\
\hline Others & 21 & 5.6 \\
\hline \multicolumn{3}{|c|}{ Receiving treatment for concomitant conditions } \\
\hline Yes & 75 & 19.9 \\
\hline No & 301 & 80.1 \\
\hline \multicolumn{3}{|c|}{ Cumulative exposure to antiretroviral drugs } \\
\hline First ART regimen & 290 & 77.2 \\
\hline 1 to 3 changes of ART regimen & 43 & 11.4 \\
\hline >3 ART regimens & 43 & 11.4 \\
\hline \multicolumn{3}{|l|}{ Occupation } \\
\hline Housework & 16 & 4.3 \\
\hline Employee & 166 & 44.1 \\
\hline Professional & 76 & 20.2 \\
\hline Housewife and employee & 39 & 10.4 \\
\hline Others & 79 & 21.0 \\
\hline \multicolumn{3}{|l|}{ Residence area } \\
\hline Distrito Federal and Estado de México & 358 & 95.2 \\
\hline Other State & 18 & 4.8 \\
\hline \multicolumn{3}{|l|}{ Socioeconomic status } \\
\hline High & 91 & 24.2 \\
\hline Medium & 224 & 59.6 \\
\hline Low & 61 & 16.2 \\
\hline
\end{tabular}

$y$, years; $\mathrm{Cl}$, confidence interval; MSM, men who have sex with men; $\mathrm{x}^{2}$, Chisquared test; $P<0.05$

Table 1: Baseline characteristics $(\mathrm{N}=376)$. 
Page 3 of 5

\begin{tabular}{|c|c|c|c|}
\hline Variable & OR & $95 \% \mathrm{Cl}$ & $P$ value \\
\hline \multicolumn{4}{|c|}{ Age } \\
\hline $18-29 y$ & 0.55 & $0.25-1.21$ & 0.096 \\
\hline $30-39 y$ & 0.38 & $0.18-0.80$ & 0.006 \\
\hline $40-49 y$ & 0.94 & $0.40-2.24$ & 0.542 \\
\hline$\geq 50 y$ & 1 & & \\
\hline \multicolumn{4}{|c|}{ Gender } \\
\hline Female & 1 & & \\
\hline Male & 0.63 & $0.37-1.08$ & 0.065 \\
\hline \multicolumn{4}{|c|}{ Occupation } \\
\hline Housework & 1 & & \\
\hline Housewife and employee & 1.78 & $0.54-5.80$ & 0.251 \\
\hline Laborer & 12.5 & $2.19-71.36$ & 0.002 \\
\hline Professional & 8.5 & $2.50-28.9$ & 0.009 \\
\hline \multicolumn{4}{|c|}{ Current smoker } \\
\hline No & 0.49 & $0.29-0.84$ & 0.007 \\
\hline Yes & 1 & & \\
\hline \multicolumn{4}{|c|}{ Alcohol consumer } \\
\hline No & 0.42 & $0.26-0.68$ & $<0.001$ \\
\hline Yes & 1 & & \\
\hline \multicolumn{4}{|c|}{ Recreational drug user } \\
\hline No & 0.38 & $0.16-0.88$ & 0.023 \\
\hline Yes & 1 & & \\
\hline
\end{tabular}

$y$, years; OR, odds ratio; $\mathrm{Cl}$, confidence interval.

Table 2: Bivariate analysis of risk factors associated with ART adherence.

\begin{tabular}{|c|c|c|c|}
\hline Characteristics & $\mathbf{N}$ & Adherence (\%) & $95 \% \mathrm{Cl}$ \\
\hline & 376 & 73.0 & $68.2-77.4$ \\
\hline \multicolumn{4}{|c|}{ Gender } \\
\hline Male & 223 & 74.8 & $69.7-79.9$ \\
\hline Female & 51 & 65.3 & $54.1-76.5$ \\
\hline \multicolumn{4}{|c|}{ Age } \\
\hline $18-29 y$ & 100 & 72.0 & $62.7-81.3$ \\
\hline $30-39 y$ & 133 & 63.9 & $55.3-72.4$ \\
\hline $40-49 y$ & 81 & 81.4 & $72.4-90.5$ \\
\hline$>50 y$ & 62 & 82.2 & $71.9-92.5$ \\
\hline \multicolumn{4}{|c|}{ Sexual preference } \\
\hline Heterosexual & 152 & 62.0 & $61.4-76.7$ \\
\hline MSM & 204 & 75.9 & $69.8-82.0$ \\
\hline Bisexual & 20 & 70.0 & $45.7-88.1$ \\
\hline \multicolumn{4}{|c|}{ Marital status } \\
\hline Single & 245 & 72.6 & $66.8-78.4$ \\
\hline Married & 56 & 75.0 & $62.7-87.2$ \\
\hline Living with partner & 46 & 63.0 & $48.0-78.0$ \\
\hline Widowed & 23 & 86.9 & $66.4-97.2$ \\
\hline Separated from partner & 6 & 83.3 & $35.8-99.5$ \\
\hline \multicolumn{4}{|c|}{ Educational level } \\
\hline Lack of school & 2 & 50 & $1.2-98.7$ \\
\hline Elementary school & 26 & 73.0 & $54.1-92.0$ \\
\hline Junior high school & 98 & 68.3 & $58.6-78.0$ \\
\hline High school & 109 & 68.8 & $59.6-77.9$ \\
\hline Degree & 95 & 76.8 & $67.8-85.8$ \\
\hline Postgraduate studies & 46 & 84.7 & $73.3-96.2$ \\
\hline \multicolumn{4}{|c|}{ Residence area } \\
\hline Distrito Federal & 224 & 70.0 & $63.8-76.3$ \\
\hline Estado de México & 134 & 76.1 & $68.5-83.7$ \\
\hline Others & 18 & 83.3 & $58.5-96.4$ \\
\hline
\end{tabular}

\begin{tabular}{|c|c|c|c|}
\hline High & 91 & 73.6 & $64.0-83.2$ \\
\hline Medium & 224 & 74.1 & $68.1-80.0$ \\
\hline Low & 61 & 67.2 & $54.6-79.8$ \\
\hline
\end{tabular}

$\mathrm{N}$, number of patients; $\mathrm{y}$, years; MSM, men who have sex with men; $\mathrm{Cl}$, confidence interval

Table 3: Prevalence of adherence to ART in patients with HIV.

\begin{tabular}{|c|c|c|c|}
\hline Characteristics & $\mathbf{N}$ & Adherence (\%) & $95 \% \mathrm{Cl}$ \\
\hline \multicolumn{4}{|c|}{ Current ARV regimen } \\
\hline TDF/FTC + NVP & 29 & 86.2 & $68.3-96.1$ \\
\hline$A B C / 3 T C+E F V$ & 27 & 81.5 & 61.9-93.7 \\
\hline TDF/FTC + EFV & 98 & 80.6 & $72.2-88.9$ \\
\hline$A B C / 3 T C+L P V / R T V$ & 27 & 77.8 & $57.7-91.3$ \\
\hline TDF/FTC + LPV/RTV & 45 & 68.9 & $54.2-83.5$ \\
\hline TDF/FTC + ATZ/RTV & 19 & 68.4 & $43.4-87.4$ \\
\hline$A B C / 3 T C+N V P$ & 22 & 68.2 & $45.1-86.1$ \\
\hline TDF/FTC + FPV/RTV & 17 & 58.8 & $32.9-81.5$ \\
\hline ZDV/3TC + LPV/RTV & 19 & 52.6 & $28.8-75.5$ \\
\hline Others & 73 & 65.8 & $54.1-77.3$ \\
\hline \multicolumn{4}{|c|}{ Adverse events related with current ARV treatment } \\
\hline Adverse effects & 56 & $85.7 \%$ & $75.65-95.77$ \\
\hline \multicolumn{4}{|c|}{ Time spent waiting for medical care or to receive drugs } \\
\hline$<30 \mathrm{~min}$ & 157 & 68.2 & $60.54-75.75$ \\
\hline $30-60 \mathrm{~min}$ & 131 & 76.3 & $68.67-83.99$ \\
\hline$>60 \mathrm{~min}$ & 88 & 76.1 & $66.66-85.61$ \\
\hline
\end{tabular}

$\mathrm{N}$, number of patients; $\mathrm{Cl}$, confidence interval; TDF, tenofovir; FTC, emtricitabine; NVP, nevirapine; ABC, abacavir; 3TC, lamivudine; EFV, efavirenz; LPV, lopinavir; RTV, ritonavir; ATZ, atazanavir; FPV, Fosamprenavir.

Table 4: Prevalence of adherence according to ART regimen.

The prevalence of adherence was calculated according to ART usage. Some ARV treatment had highest rate of adherence (Table 4).

For virological and immunological responses, the prevalence of adherence was higher $(74.8 \%)$ in patients with a CD4+ cell count of $200-500 / \mu \mathrm{L}$ (95\% CI, 68.2-81.4), and $75.1 \%$ of those patients did not show virological failure (95\% CI, 70.5-79.7; Table 5).

Other factors were found to be associated with higher adherence by multivariate analysis. These were male gender (OR, 0.43; 95\% CI, 0.22 0.83 ) and absence of alcohol use (OR, 0.27; 95\% CI, 0.12-0.58). Factors associated with non-adherence were a history of 2 ART regimens (OR, 1.95; 95\% CI, 1.05-3.62), a longer time waiting for medical care or lack of suitable ART drugs (OR, 2.40; 95\% CI, 1.22-4.70), and persistent viremia (OR, 2.72; 95\% CI, 1.42-5.19; $\mathrm{P}<0.005$; Table 6).

\section{Discussion}

We aimed to investigate the prevalence of and risk factors associated with adherence to ART. There was a high level of adherence in these patients with HIV/AIDS (73\%; 95\% CI, 68.2-77.4\%).

Treatment adherence requires patient commitment, and the physician needs to explain the importance of both factors for achieving therapeutic success. Good adherence is associated with better outcomes, including an improved quality of life, higher CD4+ cell count, and lower health care costs [2]. We found here that male gender and absence of alcohol use were positively and significantly associated with better adherence, whereas a history of $\geq 2$ ART regimens and lack of supply of the necessary drugs were factors associated with nonadherence. Non-adherence was directly associated with the presence of persistent viremia. 
Our study is similar to the study of Mbopi-Kéou et al. that analyzed a population of 356 patients and found a calculated adherence of $51.5 \%$ and a declared adherence of $80.2 \%$ [14]. Margalho et al. in a study conducted in 2011 in Portugal found lower levels of non-adherence to ART compared with our data. They applied two measuring instruments and calculated a non-adherence rate of $17.5 \%$ [15], whereas in our study $27 \%$ of the subjects were non-adherent to ART.

In other studies, including ours, most of the subjects were men. For example, Piña-López et al. reported that $68.8 \%$ were men and $58.1 \%$ were not married [16], similar to our patients, where $65.2 \%$ were single. For educational level, they observed that over half of the patients (54.9\%) had completed high school; by contrast, we found that only $26.1 \%$ of patients had completed junior high school and $29 \%$ had completed high school (Table 1). In Mexico, studies conducted in the north of the country in 2006 by Peñarrieta et al. and Piña-López et al. reported different rates of adherence (50-52\%). These used the adherence questionnaire VPAD24 [12,17]. In our study, we decided to use the SMAQ questionnaire because it is easier to use, with a sensitivity of $72 \%$ and specificity of $91 \%$ [13]. In this way, we aimed to capture the true nonadherent population in a large Latin American sample of HIV-positive patients.

\begin{tabular}{|c|c|c|c|}
\hline Characteristics & $\mathbf{N}$ & $\%$ & $95 \% \mathrm{Cl}$ \\
\hline \multicolumn{4}{|c|}{ CD4+ cell count $/ \mu \mathrm{L}$} \\
\hline$>500$ & 135 & 74.0 & $66.3-81.8$ \\
\hline $200-500$ & 179 & 74.8 & $68.2-81.4$ \\
\hline$<200$ & 62 & 64.5 & $51.8-77.2$ \\
\hline \multicolumn{4}{|c|}{ HIV-1 RNA viral load in copies/mL } \\
\hline$<20$ & 270 & 80.0 & $75-84.9$ \\
\hline $20-199$ & 81 & 65.4 & $54.4-76.4$ \\
\hline $200-999$ & 12 & 33.3 & $9.9-65.1$ \\
\hline$>1000$ & 13 & 7.7 & $0.2-36.0$ \\
\hline \multicolumn{4}{|c|}{ Persistent viremia } \\
\hline Yes & 26 & 30.8 & $11.1-50.4$ \\
\hline No & 334 & 77.2 & $72.6-81.8$ \\
\hline Blip & 16 & 50.0 & $24.6-75.3$ \\
\hline \multicolumn{4}{|c|}{ Virological failure } \\
\hline Yes & 14 & 14.2 & $1.7-42.8$ \\
\hline No & 362 & 75.1 & $70.5-79.7$ \\
\hline
\end{tabular}

$\mathrm{N}$, number of patients; $\mathrm{Cl}$, confidence interval

Blip, only one HIV-1 RNA viral load elevation less than 1,000 copies/mL

Table 5: Prevalence of adherence to ART: immunological and virological variables.

\begin{tabular}{|c|c|c|c|}
\hline Characteristics & OR & $95 \% \mathrm{Cl}$ & $P$ value \\
\hline \multicolumn{4}{|c|}{ Gender } \\
\hline Female & 1 & & \\
\hline Male & 0.43 & $0.22-0.83$ & 0.012 \\
\hline \multicolumn{4}{|c|}{ Alcohol consumption } \\
\hline Yes & 1 & & \\
\hline No & 0.27 & $0.12-0.58$ & 0.001 \\
\hline \multicolumn{4}{|c|}{ Number of prior ART regimens } \\
\hline 1 & 1 & & \\
\hline$\geq 2$ & 1.95 & $1.05-3.62$ & 0.033 \\
\hline \multicolumn{4}{|c|}{$\begin{array}{l}\text { Time spend attending medical care or receiving drugs (more than } \mathbf{3 0} \\
\text { minutes) }\end{array}$} \\
\hline No & 1 & & \\
\hline Yes & 2.403 & $1.22-4.70$ & 0.011 \\
\hline
\end{tabular}

OR, odds ratio; $\mathrm{Cl}$, confidence interval

Table 6: Multivariate analysis of factors associated with ART adherence.
Difficulty in accessing antiretroviral drugs is a clear risk factor for nonadherence, and institutions should take more control of this. Regarding the subjects' prior ART experience, a history of $\geq 2$ regimens was a risk factor for persistent non-adherence, and we found that these patients showed virological failure more frequently.

In our study, adverse events were not statistically significant, in contrast to a meta-analysis of 19 studies conducted by Al-Dakkak et al., who found lower adherence in patients with adverse effects to ART compared with those without [10].

Our results are similar to those of some clinical trials when they found a higher frequency of virological failure in women, factors associated with non-adherence, antiretroviral discontinuation, and poor virologic response in univariate analyses were being the primary caregiver for children, unemployment, and transportation difficulties, respectively, and the major sex-based differences in response may be due to higher discontinuation rates in women $[17,18]$.

It is well known that adherence depends on the regimen simplicity. Several studies have evaluated this association and concluded that decreasing the pill burden and dosing frequency is associated with increased adherence [19]. In our study, treatment regimens that had greater adherence were tenofovir/emtricitabina plus nevirapina, followed by abacavir/lamivudina plus efavirenz and tenofovir/ emtricitabina plus efavirenz and those who had lower adherence rate were protease inhibitors based regimens. This results were similar to those reported by Sterrantino et al. [20], who conclude that $30 \%$ of patients with protease inhibitors based regimen did not adhere to ART and only $26 \%$ and $25 \%$ of patients in a once daily and twice daily regimen, respectively, did not adhere. In this study, 30\%, 19\% and $14 \%$ of patients did not adhere to protease inhibitors regimen, once daily and twice daily regimens, respectively. This better adherence with simple regimens and mostly free of protease inhibitors is associated with a lowest number of pills, the dose frequency and the adverse effects which have the greatest impact on patients' perceived ability to adhere to ARV medication regimen. Cohen et al, has been shown that patients on a once daily single tablet regimen consistently achieve higher adherence levels than patients on 2 pills per day regimens and that single tablet regimen was significantly better at achieving $>90 \%$ adherence rates when compared with other multi-pill regimens, despite an once daily schedule [21]. In our medical care center do not have single tablet regimens but simple regimen such as tenofovir/ emtricitabine plus Nevirapina, abacavir/lamivudina plus Efavirenz and tenofovir/emtricitabine plus Efavirenz were associated with high adherence to ART in this study.

Finally, in contrast with a systematic review by Lankowski AL et al., when they found that geographic and transportation-related barriers were associated with worse outcomes throughout the continuum of HIV care. These associations were observed with lack of transportation and inability to afford the cost transportation. Our population lived in cities with access to transportation to arrive the HIV clinic, only $4 \%$ were living in other states [22].

In conclusion in the era of ART as prevention for transmission of HIV as well as treatment for HIV-positive individuals irrespective of CD4 cell counts, the importance of adherence has grown. Treatment failure reduces future treatment options and therefore long-term clinical success as well as increases the possibility of developing drug resistant mutations. The overall prevalence of ART adherence in these HIV-infected adults was $73 \%$. Being male and a lack of alcohol use were factors associated with higher rates of adherence, whereas previous use of ART, more ARV regimens, and a longer time waiting for medical 
care or drugs, were associated with nonadherence in this HIV-infected population. Incomplete ART adherence is associated with persistent viremia.

In summary, we assessed risk factors that could help us to identify patients at risk of nonadherence. These factors could be modified in many patients to increase the possibility of virological success.

\section{Competing Interests}

We don't have conflict of interest.

\section{Acknowledgment}

The authors would like to thank all the study team, the cooperation extended by the Infectious Diseases Department, and Epidemiology Department, National Medical Center "La Raza"

\section{Funding Acknowledgment}

The authors supported this study.

\section{References}

1. World Health Organization (2013) Global update on HIV treatment 2013: Results, impact and opportunities. World Health Organization, Kuala Lumpur.

2. Secretaría de Salud, Censida (2014) Guía de manejo antirretroviral de las personas con VIH. Censida, Mexico D.F.

3. World Health Organization (2010) Antiretroviral therapy for HIV infection in adults and adolescents: Recommendations for a public health approach. World Health Organization, Geneva, Switzerland.

4. World Health Organization (2006) WHO case definitions of HIV for surveillance and revised clinical staging and immunological classification of HIV-related disease in adults and children. World Health Organization, Geneva, Switzerland.

5. Vandamme AM, Camacho RJ, Ceccherini-Silberstein F, de Luca A, Palmisano $\mathrm{L}$, et al. (2011) European recommendations for the clinical use of HIV drug resistance testing: 2011 update. AIDS Rev 13: 77-108.

6. Jones G, Hawkins K, Mullin R, Nepusz T, Naughton DP, et al. (2012) Understanding how adherence goals promote adherence behaviours: A repeated measure observational study with HIV seropositive patients. BMC Public Health 12: 587.

7. Organización Mundial de la Salud (2004) Adherencia a los tratamientos a largo plazo: Pruebas para la acción. Organización Mundial de la Salud, Geneva, Switzerland.

8. Smith KY (2002) Selected metabolic and morphologic complications associated with highly active antiretroviral therapy. J Infect Dis 185 Suppl 2: S123-127.

9. Ortego C, Huedo-Medina TB, Llorca J, Sevilla L, Santos P, et al. (2011) Adherence to highly active antiretroviral therapy (HAART): a meta-analysis. AIDS Behav 15: 1381-1396.
10. Al-Dakkak I, Patel S, McCann E, Gadkari A, Prajapati G, et al. (2013) The impact of specific HIV treatment-related adverse events on adherence to antiretroviral therapy: a systematic review and meta-analysis. AIDS Care 25: 400-414.

11. Knobel H, Alonso J, Casado JL, Collazos J, González J, et al. (2002) Validation of a simplified medication adherence questionnaire in a large cohort of HIVinfected patients: the GEEMA Study. AIDS 16: 605-613.

12. Peñarrieta MI, Kendall T, Martinez N, Rivera AM, Gonzales N, et al. (2009) Adherencia al tratamiento antirretroviral en personas con VIH en Tamaulipas, México. Rev Perú Med Exp Salud Pública 26: 333-337.

13. Rodríguez Chamorro MA, García-Jiménez E, Amariles $P$, Rodríguez Chamorro A, Faus MJ (2008) [Review of the test used for measuring therapeutic compliance in clinical practice]. Aten Primaria 40: 413-418.

14. Mbopi-Kéou FX, Dempouo Djomassi L, Monebenimp F (2012) [Study of factors related to adherence to antiretroviral therapy among patients followed at HIV/ AIDS Unit in the District Hospital of Dschang, Cameroon]. Pan Afr Med J 12: 55.

15. Margalho R, Pereira M, Ouakinin S, Canavarro MC (2011) [Adherence to HAART, quality of life and psychopathological symptoms among HIVIAIDS infected patients]. Acta Med Port 24 Suppl 2: 539-548.

16. Piña-López JA, Corrales-Rascón AE, Mungaray-Padilla K, Valencia Vidrio MA (2006) Instrument for measuring psychological variables and adherence to treatment behavior in persons who are seropositive for HIV (VPAD-24). Rev Panamá Salud Publica 19: 217-228.

17. Squires K, Feinberg J, Bridge DA, Currier J, Ryan R, et al. (2013) Insights on GRACE (Gender, Race, And Clinical Experience) from the patient's perspective: GRACE participant survey. AIDS Patient Care STDS 27: 352-362.

18. Pérez-Molina JA, Mora Rillo M, Suárez-Lozano I, Casado-Osorio JL, Teira Cobo R, et al. (2012) Response to combined antiretroviral therapy according to gender and origin in a cohort of naïve HIV-infected patients: GESIDA-5808 study. HIV Clin Trials 13:131-141.

19. Parienti JJ, Bangsberg DR, Verdon R, Gardner EM (2009) Better adherence with once-daily antiretroviral regimens: a meta-analysis. Clin Infect Dis 48: 484 488 .

20. Sterrantino G, Santoro L, Bartolozzi D, Trotta M, Zaccarelli M (2012) Selfreported adherence supports patient preference for the single tablet regimen (STR) in the current cART era. Patient Prefer Adherence 6: 427-433.

21. Cohen C, Meyers J, Davis K (2013) Association between daily antiretrovira pill burden and treatment adherence, hospitalisation risk, and other healthcare utilisation and costs in a US medicaid population with HIV. BMJ Open 3: e003028.

22. Lankowski AJ, Siedner MJ, Bangsberg DR, Tsai AC (2014) Impact of geographic and transportation-related barriers on HIV outcomes in sub-Saharan Africa: a systematic review. AIDS Behav 18: 1199-1223. 